\title{
TABLETOP EXERCISE SIMULATION FOR HOSPITAL DISASTER PREPAREDNESS: A SYSTEMATIC REVIEW
}

\author{
Diah Mutiarasari'), Sukri Palutturi²), Fridawaty Rivai3), \\ Nurmala Sari4), Miranti5) \\ 1)Doctoral Program, Faculty of Public Health, Hasanuddin University \\ 2) Department of Health Policy Administration, \\ Faculty of Public Health, Hasanuddin University \\ 3,4)Department of Hospital Management, \\ Faculty of Public Health, Hasanuddin University \\ 5)Department of Public Health - Community Medicine, \\ Faculty of Medicine, Tadulako University
}

\begin{abstract}
Background: Hospitals need disaster preparedness. Training model through a participatory approach to improve the knowledge and skills of officers so that they will better prepare for sudden disasters. One of the training media used is a simulation of the tabletop exercise with three level collaboration using a disaster scenario. This training model is intended to improve knowledge and skills in disaster preparedness management. This study aimed to review systematically whether tabletop exercise simulation improved disaster preparedness in hospital.

Subjects and Method: This was a systematic review using the Preferred Reporting Items for Systematic Reviews and Meta-Analyses (PRISMA). The independent variable was tabletop exercise. The dependent variable was disaster preparedness. Research articles from November 2020 to January 2021 were accessed from Scopus, Pubmed, Proquest, Cambridge Core, Science Direct, and Google Scholar. The search keywords consisted of two domains, "Simulation" (tabletop exercise simulation OR simulationbased disaster) and "Hospital Disaster Preparedness." Initially 470 studies were identified. Six studies fulfilled the inclusion criteria of the review.

Results: This systematic review showed that tabletop exercise improved knowledge and skills in disaster preparedness management in hospital.

Conclusion: Tabletop exercise improves knowledge and skills in disaster preparedness management in hospital.
\end{abstract}

Keywords: tabletop exercise, simulation, hospital, disaster preparedness

\section{Correspondence:}

Diah Mutiarasari. Faculty of Public Health, Hasanuddin University. Jl. Perintis Kemerdekaan 10, Tamalanrea, Makassar, South Sulawesi 90245. Email: diah.mutiarasari@yahoo.com. Mobile: 0811452984. 